\title{
SUPERAÇÃO DE DORMÊNCIA EM CAPIM-BRAQUIÁRIA
}

\author{
LIMA, Kamilla Nascimento ${ }^{1}$ \\ TEODORO, Paulo Eduardo ${ }^{2}$ \\ PINHEIRO, Gisele da Silva ${ }^{1}$ \\ PEREIRA, Ana Carolina ${ }^{1}$ \\ TORRES, Francisco Eduardo ${ }^{1}$
}

RESUMO: A Brachiaria brizantha é a espécie forrageira mais utilizada atualmente no Brasil e exportada para diversos países. Para uma boa formação de pastagem, é fundamental que as sementes apresentem alta germinação. É comum, que algumas cultivares desta espécie, apresente dormência natural, interferindo negativamente na germinação, trazendo grandes prejuízos ao produtor. Desta forma, o objetivo deste trabalho foi avaliar diferentes métodos para a superação de dormência em B. brizantha cultivares Marandú, MG5 e Piatã. O trabalho foi realizado no Laboratório de Matéria Orgânica e Microbiologia do Solo (LAMOMIS), na Universidade Estadual de Mato Grosso do Sul - Unidade Universitária de Aquidauana, no período de setembro a outubro do ano de 2013. O experimento foi conduzido em delineamento inteiramente casualizado, com quatro tratamentos para a superação de dormência $\left(\mathrm{H}_{2} \mathrm{SO}_{4}, \mathrm{KNO}_{3}\right.$, água aquecida e testemunha) e cinco repetições. As contagens de germinação foram realizadas aos 7, 14, 21 e 28 dias após o início do teste. Foi encontrada diferença significativa $(\mathrm{p}<0,01)$ para as contagens, dentro de cada época de avaliação, sendo que o tratamento térmico apresentou o melhor resultado para a germinação das sementes, onde cultivar Piatã apresentou melhor desempenho.

Palavras-chave: Germinação. Marandú. MG5. Piatã.

SUMMARY: Brachiaria brizantha is forage more currently used in Brazil and exported to several countries. For a good pasture formation, it is essential that exhibit high seed germination. It is common that some cultivars of this species provide natural dormancy, germination interfering negatively, bringing huge losses to the producer. This way, was evaluated different methods of scarification in braquiária cultivars (Marandú, MG5 and Piata). The work was performed at the Laboratory of Organic Matter and Soil Microbiology (LAMOMIS), the State University of Mato Grosso do Sul - Aquidauna University of Unity, from September to October of the year 2013. The experiment was conducted in a completely randomized with four treatments to overcome dormancy ( $\mathrm{H} 2 \mathrm{SO} 4$, $\mathrm{KNO} 3$, heated water and control) and five replications. Germination counts were taken at 7, 14, 21 and 28 days after the start of the test. Significant difference $(\mathrm{p}<0.01)$ was found for the same within each evaluation period, and the heat treatment showed the best results for seed germination, but to cultivate the best performance in this period was the Piatã.

Keywords: Germination. Marandú. MG5. Piatã.

\section{INTRODUÇÃO}

A expansão das áreas de pastagens cultivadas com espécies do gênero Brachiaria tem aumentado no Brasil, quando comparada com outras forrageiras, e vem ganhando espaço, principalmente por ser rústica, permitindo adaptação as mais variadas condições, tanto de clima quanto de solo. Atualmente, o país exporta semente com valor cultural em torno de $80 \%$ para cerca de 40 países, sendo o maior produtor e exportador de sementes forrageiras tropicais do mundo (CARDOSO et al., 2014).

As sementes desse gênero apresentam dificuldades para germinar tanto em laboratório quanto a campo, e o principal fator que contribui para que isto ocorra é a presença de dormência. Nas gramíneas forrageiras tropicais, a expressão da dormência se associa às causas fisiológicas presentes em sementes recém-colhidas, progressivamente suprimidas durante o armazenamento, ou às causas físicas, provavelmente relacionadas às restrições impostas pela cobertura da semente à entrada de oxigênio, 
umidade, elevadas temperaturas, apresentando, entre outros fatores, desuniformidade de maturação (SILVA et al., 2014).

A maioria de trabalhos realizados para a superação de dormência de sementes de braquiária menciona o tratamento com ácido sulfúrico. Conforme Marcos Filho (2005), o mesmo é utilizado por promover a permeabilidade do tegumento a água e as trocas gasosas. A escarificação química é um método utilizado nos lotes de sementes de B. brizantha comercializados, todavia, apresenta riscos aos trabalhadores e ao meio ambiente e, além disso, pode promover danos às sementes. Respostas incipientes sobre atuação do $\mathrm{KNO}_{3}$ no condicionamente fisiológico das sementes são encontradas, como as citadas por Bonome et al. (2006), que relataram que este sal de baixo peso molecular, pode ter penetrado nos tecidos das sementes de braquiária causando fitotoxidez.

A escolha de tratamentos eficientes para a superação da dormência varia pelos fatores mencionados anteriormente. Deste modo, são vários os métodos que podem ser empregados para a superação da mesma, porém os mais utilizados são tratamentos químicos, térmicos e mecânicos. A eficiência da formação de uma pastagem está intimamente ligada com a utilização de sementes com alta qualidade e, pesquisas para a melhoria da qualidade fisiológica das sementes e superação da dormência são de extrema importância para a sustentabilidade do sistema de produção.

Este trabalho teve como objetivo avaliar métodos de superação de dormência em sementes de cultivares de B. brizantha.

\section{MATERIAL E MÉTODO}

O experimento foi conduzido entre os meses de setembro a outubro no ano de 2013 no Laboratório de Matéria Orgânica e Microbiologia do Solo da Universidade Estadual de Mato Grosso do Sul, Unidade Universitária de Aquidauana.

O experimento teve três fatores de estudo, sendo avaliada a interação entre três cultivares de $B$. brizantha submetidas a quatro tratamentos para superação de dormência. Foram utilizadas as cultivares Piatã, Marandu e MG-5. Os tratamentos consistiram de escarificação com ácido sulfúrico $\left(\mathrm{H}_{2} \mathrm{SO}_{4}\right)$, tratamento térmico com água aquecida, nitrato de potássio $\left(\mathrm{KNO}_{3}\right)$ e a testemunha.

A metodologia foi proposta segundo MAPA - Regras para Análise de Sementes (BRASIL, 2009) com os seguintes procedimentos:

a) Ácido sulfúrico $\left(\mathrm{H}_{2} \mathrm{SO}_{4}\right)$ : As sementes foram imersas em $\mathrm{H}_{2} \mathrm{SO}_{4}$ concentrado durante 15 minutos e, em seguida, lavadas em água corrente por 5 minutos e secas à sombra;

b) Tratamento térmico: As sementes foram imersas em Béqueres de $50 \mathrm{~mL}$, em água destilada aquecida a $60^{\circ} \mathrm{C}$ durante 5 minutos;

c) Nitrato de potássio $\left(\mathrm{KNO}_{3}\right)$ : As sementes foram embebidas em Béqueres de $20 \mathrm{~mL}$, em uma solução de $0,2 \%$ de $\mathrm{KNO}_{3}$;

d) Testemunha: Foram utilizadas sementes, sem qualquer acondicionamento. O substrato de germinação foi umedecido com água destilada.

Em seguida, 325 sementes foram colocadas em Placas de Petri $(100 \times 20 \mathrm{~mm})$, sobre duas folhas de papel filtro umedecido com água destilada, com exceção do tratamento de $\mathrm{KNO}_{3}$ com a solução preparada. Logo após foram levadas em germinador tipo BOD, para ocorrer o processo germinativo, permanecendo no seu interior durante 28 dias sob 16 horas de luz à $35^{\circ} \mathrm{C}$ e por 8 horas de fase escura à $20^{\circ} \mathrm{C}$. Diariamente os papéis eram umedecidos com água destilada, conforme Gaspar-Oliveira et al. (2007). 
A eficiência dos tratamentos sobre cada cultivar foi avaliada aos 7, 14, 21 e 28 dias após a semeadura (DAS), sendo os resultados expressos em porcentagem de germinação acumulada.

Foi utilizado um delineamento inteiramente casualizado em esquema de parcelas subdivididas, com cinco repetições, as parcelas foram as cultivares e as subparcelas os diferentes tratamentos avaliados, contendo 325 sementes para cada tratamento, totalizando 1.300 sementes.

Através do software estatístico Assistat (SILVA; AZEVEDO, 2002) efetuou-se análise de variância e para os parâmetros que apresentaram significância $(\mathrm{p}<0,01)$, foi aplicado teste de comparação de médias de Tukey, a $5 \%$ de probabilidade.

\section{RESULTADO E DISCUSSÃO}

São demonstrados os valores do teste $\mathrm{F}$ para as fontes de variação da presente pesquisa, onde se constatou significância $(p<0,01)$ para as mesmas, dentro de cada época de avaliação (Tabela 1$)$.

Tabela 1. Análise de variância (ANOVA) da porcentagem de germinação das cultivares de Brachiaria brizantha submetidas a diferentes tratamentos para quebra de dormência, dentro de cada época de avaliação em Aquidauana, MS, 2013.

\begin{tabular}{lllll}
\hline Fontes de variação & 07 DAS & 14 DAS & 21 DAS & 28 DAS \\
\hline Cultivares & $52,40^{* *}$ & $41,90^{* *}$ & $29,48^{* *}$ & $20,06^{* *}$ \\
Tratamentos & $20,82^{* *}$ & $23,97^{* *}$ & $22,97^{* *}$ & $8,83^{* *}$ \\
Cultivares x Tratamentos & $5,59^{* *}$ & $7,43^{* *}$ & $6,99^{* *}$ & $4,86^{* *}$ \\
\hline CV Cultivares (\%) & 41,31 & 34,23 & 32,04 & 22,61 \\
CV Tratamentos (\%) & 55,11 & 47,51 & 32,34 & 17,33 \\
\hline ** Significativo pelo teste F ao nível de 1\% de probabilidade; DAS = dias após a semeadura; CV = coeficiente de \\
variação em \%.
\end{tabular}

Os valores médios de porcentagem de germinação aos 7 e 14 DAS de cultivares de B. brizantha submetidas a diferentes tratamentos para superação de dormência estão apresentados, respectivamente, na Tabela 2 e na Tabela 3.

Tabela 2. Valores médios de porcentagem de germinação de cultivares de Brachiaria brizantha submetidas a diferentes tratamentos para superação de dormência aos sete dias após a semeadura. Aquidauana, MS, 2013.

\begin{tabular}{llllll}
\hline \multirow{2}{*}{ Cultivares } & Testemunha & Térmico & $\mathrm{H}_{2} \mathrm{SO}_{4}$ & $\mathrm{KNO}_{3}$ & \multirow{2}{*}{ Média } \\
\hline Piatã & $14,53 \mathrm{aA}$ & $17,11 \mathrm{aA}$ & $0,25 \mathrm{aB}$ & $12,86 \mathrm{aA}$ & 11,19 \\
Marandu & $4,92 \mathrm{bB}$ & $11,94 \mathrm{aA}$ & $1,66 \mathrm{aB}$ & $5,60 \mathrm{bB}$ & 6,03 \\
MG5 & $0,12 \mathrm{bB}$ & $6,65 \mathrm{bA}$ & $2,52 \mathrm{aAB}$ & $0,55 \mathrm{bAB}$ & 2,46 \\
\hline Média & 6,53 & 11,90 & 1,48 & 6,34 & --- \\
\hline
\end{tabular}

Letras iguais maiúsculas nas linhas e minúsculas nas colunas não diferem entre si pelo teste de Tukey a $5 \%$ de probabilidade.

A cv. Piatã foi superior estatisticamente em relação às demais cultivares, sendo o tratamento térmico o que obteve maior eficiência para a quebra de dormência aos 7 e 14 DAS. Dentro da interação Cultivares x Tratamentos, observa-se que para a testemunha e o $\mathrm{KNO}_{3}$, a cv. Piatã apresentou maior porcentagem de germinação, entretanto não se diferenciou estatisticamente sobre a cv. Marandu nos tratamentos térmico e com $\mathrm{H}_{2} \mathrm{SO}_{4}$. 
Tabela 3. Valores médios de porcentagem de germinação de cultivares de Brachiaria brizantha submetidas a diferentes tratamentos para superação de dormência aos 14 dias após a semeadura (DAS). Aquidauana, MS, 2013.

\begin{tabular}{llllll}
\hline \multirow{2}{*}{ Cultivares } & \multicolumn{4}{c}{ Tratamentos } & \multirow{2}{*}{ Média } \\
\hline Piatã & Testemunha & Térmico & $\mathrm{H}_{2} \mathrm{SO}_{4}$ & $\mathrm{KNO}_{3}$ & \\
Marandu & $23,94 \mathrm{aA}$ & $28,68 \mathrm{aA}$ & $0,43 \mathrm{aB}$ & $22,21 \mathrm{aA}$ & $18,82 \mathrm{a}$ \\
MG5 & $11,51 \mathrm{bB}$ & $21,85 \mathrm{abA}$ & $3,75 \mathrm{aB}$ & $10,34 \mathrm{bB}$ & $11,86 \mathrm{~b}$ \\
\hline Média & $0,68 \mathrm{cB}$ & $16,37 \mathrm{bA}$ & $8,49 \mathrm{aAB}$ & $0,68 \mathrm{cB}$ & $6,56 \mathrm{c}$ \\
\hline
\end{tabular}

Letras iguais maiúsculas nas linhas e minúsculas nas colunas não diferem entre si pelo teste de Tukey a $5 \%$ de probabilidade.

Para a cv. Piatã, o tratamento com $\mathrm{H}_{2} \mathrm{SO}_{4}$ foi prejudicial, obtendo os menores percentuais de germinação. $\mathrm{O}$ tratamento térmico demonstrou maior eficiência para as demais cultivares, porém não se diferenciou estatisticamente do $\mathrm{H}_{2} \mathrm{SO}_{4}$ para a cv. MG5. Conforme Souza (2007), as espécies do gênero Brachiaria possuem um tegumento duro e impermeável que pode atrapalhar os mecanismos de embebição e geminação. De acordo com estes autores, com a utilização de tratamentos químicos é possível remover esta estrutura, melhorando a germinação no aspecto de quantidade.

O método de escarificação com ácido sulfúrico tem sido utilizado principalmente em sementes que tem dificuldade em permeabilização à água, pois algumas apresentam envoltórios que evitam ou retardam a germinação (ELLIS et al., 1985). Corroborando com este trabalho, Previero et al. (1998) puderam confirmar em seus estudos que a escarificação com este ácido acabou prejudicando a superação inicial da dormência em B. brizantha.

Estudos realizados com sementes de $B$. humidicola, demonstraram que há indicações de que sementes recém-colhidas devem permanecer armazenadas por 6 a 9 meses, ou serem escarificadas com ácido sulfúrico, antes da semeadura, como forma de reduzir a intensidade da dormência (COSTA et al., 2011).

Aos 21 dias, a cv. Piatã manteve a maior porcentagem de germinação em relação às outras cultivares, que não diferenciaram entre si. O tratamento térmico, novamente, demonstrou-se superior aos demais. Com relação à interação Cultivares x Tratamentos, a cv. Piatã apresentou maior porcentagem de germinação em todos os tratamentos, embora não tenha diferido estatisticamente da MG-5 no tratamento com $\mathrm{H}_{2} \mathrm{SO}_{4}$. Não houve diferença quanto os tratamentos aplicados para superação de dormência na cv. MG-5, enquanto nas demais cultivares, o tratamento térmico obteve maior eficiência (Tabela 4).

Tabela 4. Valores médios de porcentagem de germinação de cultivares de Brachiaria brizantha submetidas a diferentes tratamentos para superação de dormência aos 21 dias após a semeadura (DAS). Aquidauana, MS, 2013.

\begin{tabular}{llllll}
\hline \multirow{2}{*}{ Cultivares } & \multicolumn{4}{c}{ Tratamentos } & \multicolumn{2}{l}{ Média } \\
\hline Piatã & Testemunha & Térmico & $\mathrm{H}_{2} \mathrm{SO}_{4}$ & $\mathrm{KNO}_{3}$ & \\
Marandu & $12,74 \mathrm{aB}$ & $32,62 \mathrm{aA}$ & $6,52 \mathrm{abC}$ & $26,46 \mathrm{aB}$ & $23,59 \mathrm{a}$ \\
MG5 & $22,66 \mathrm{bA}$ & $4,51 \mathrm{bC}$ & $11,42 \mathrm{bBC}$ & $12,45 \mathrm{~b}$ \\
Média & $10,89 \mathrm{bA}$ & $17,29 \mathrm{bA}$ & $14,03 \mathrm{aA}$ & $8,98 \mathrm{bA}$ & $12,80 \mathrm{~b}$ \\
\hline
\end{tabular}

Letras iguais maiúsculas nas linhas e minúsculas nas colunas não diferem entre si pelo teste de Tukey a $5 \%$ de probabilidade. 
Um fator relevante, de acordo com Garcia e Cicero (1992) é a espécie e/ou cultivar envolvida, pois suas características morfológicas interferem na superação da dormência. Entretanto, na literatura são escassos os dados de comparação entre cultivares de B. brizantha, uma vez que a maioria dos trabalhos avalia a superação de dormência de uma cultivar isoladamente.

A cv. Piatã obteve maior porcentagem final de germinação em relação as demais cultivares, o que permite informar ao produtor que a utilização de sementes da cv. Piatã proporcionará maior germinação em relação as demais cultivares avaliadas (Tabela 5).

Tabela 5. Valores médios de porcentagem de germinação de cultivares de Brachiaria brizantha submetidas a diferentes tratamentos para superação de dormência aos 28 dias após a semeadura (DAS). Aquidauana, MS, 2013.

\begin{tabular}{llllll}
\hline \multirow{2}{*}{ Cultivares } & \multicolumn{4}{c}{ Tratamentos } & \multirow{2}{*}{ Média } \\
\hline Piatã & Testemunha & Térmico & $\mathrm{H}_{2} \mathrm{SO}_{4}$ & $\mathrm{KNO}_{3}$ & \\
Marandu & $29,40 \mathrm{aB}$ & $38,16 \mathrm{aA}$ & $23,45 \mathrm{aB}$ & $32,92 \mathrm{aAB}$ & $30,23 \mathrm{a}$ \\
MG5 & $14,57 \mathrm{bB}$ & $27,19 \mathrm{bA}$ & $8,18 \mathrm{bB}$ & $14,65 \mathrm{bB}$ & $16,15 \mathrm{~b}$ \\
\hline Média & $16,12 \mathrm{bA}$ & $18,45 \mathrm{bA}$ & $23,95 \mathrm{aA}$ & $19,14 \mathrm{bA}$ & $19,42 \mathrm{~b}$ \\
\hline
\end{tabular}

Letras iguais maiúsculas nas linhas e minúsculas nas colunas não diferem entre si pelo teste de Tukey a $5 \%$ de probabilidade.

Aliado a isto, o tratamento térmico apresentou maior eficiência para a quebra de dormência da espécie B. brizantha, independente da cultivar. Estes resultados diferem dos obtidos por Silva et al. (2014), que ao avaliarem a superação de dormência em cultivares de B. brizantha, verificaram que o tratamento térmico foi mais eficaz em relação ao $\mathrm{H}_{2} \mathrm{SO}_{4}$ e $\mathrm{KNO}_{3}$.

Os demais tratamentos não se diferenciaram entre si. Isto contradiz o resultado encontrado por Gaspar-Oliveira et al. (2007), que verificaram que a escarificação de sementes da cv. Marandu com $\mathrm{H}_{2} \mathrm{SO}_{4}$ resulta em maior germinação no menor tempo, possibilitando o encerramento do teste de germinação 11 dias após a sua instalação.

Para a quebra de dormência da cv. Piatã, tanto o tratamento térmico como o de escarificação com $\mathrm{KNO}_{3}$ pode ser recomendado, entretanto para a cv. Marandu, apenas o primeiro demonstrou-se viável. Os melhores resultados obtidos pelo tratamento térmico indicam que nestas cultivares existem a dormência física na cobertura da semente. Com relação a esse fenômeno, Popinigis (1977) afirmou que a impermeabilidade ao oxigênio é encontrada em muitas espécies de gramíneas, acrescentou ainda, que determinadas estruturas, tais como pericarpo, tegumento e mesmo paredes celulares, restringem as trocas gasosas.

De outra parte, o grande incremento que o com $\mathrm{KNO}_{3}$ promoveu na germinação de sementes da cv. Piatã sugere que nesta cultivar ocorre, também, a dormência química. Carvalho e Nakagawa (1983) informam que na maioria dos casos em que o $\mathrm{KNO}_{3}$ atua efetivamente na superação de dormência, isso ocorre em sementes de gramíneas, pois, nelas, a dormência seria devida à ocorrência de substâncias fixadoras de oxigênio no complexo película-pericarpo (compostos fenólicos).

Para a cv. MG-5, não houve diferença com relação aos tratamentos avaliados na porcentagem final de germinação, o que indica que não há necessidade de utilização dos mesmos para a quebra de dormência nesta cultivar.

De modo geral, os percentuais finais de germinação obtidos neste trabalho para as cultivares Piatã, Marandu e MG-5 foram inferiores aos obtidos por Silva et al. (2014), que obtiveram 76,1, 65,7 e 63,7\% de 
germinação aos 28 DAS, respectivamente para estas cultivares. Isto revela a necessidade de pesquisas futuras envolvendo a utilização de diversos tratamentos para a quebra da dormência de cultivares do gênero Brachiaria, para alicerçar a formulação de alternativas tecnológicas que aliem, em sua aplicação, eficiência operacional e segurança ambiental.

\section{CONCLUSÃO}

A cultivar Piatã apresentou maior porcentagem final de germinação em relação as demais.

O tratamento térmico foi mais eficiente para superação de dormência em Brachiaria brizantha, porém nenhum tratamento foi proporcionou germinação adequada para as sementes.

Para a quebra de dormência da cv. Piatã, tanto o tratamento térmico como o de embebição no $\mathrm{KNO}_{3}$ pode ser recomendado. Para a cv. Marandu, apenas o tratamento térmico demonstrou-se viável. Para a cultivar MG5 recomenda-se o tratamento térmico e com escarificação com ácido sulfúrico.

\section{REFERÊNCIAS}

BRASIL. Ministério da Agricultura, Pecuária e Abastecimento. Regras para análise de sementes. Brasília, 2009. Disponível em: http://www.agricultura.gov.br/images/MAPA/arquivos_portal/ACS/sementes_web.pdf . Acesso em: 20 set. 2013.

CARDOSO, E. D. et al.. Desempenho fisiológico e superação de dormência em sementes de Brachiaria brizantha submetidas a tratamento químico e envelhecimento artificial. Semina: Ciências Agrárias, Londrina, v. 35, n. 1, p. 21-38, 2014.

COSTA, C. J.; ARAÚJO, R. B. de; BÔAS, H.D.da C. V.; Tratamentos para a superação de dormência em sementes de Brachiaria humidicola. Pesq. Agropec. Trop., Goiânia, v. 41, n. 4, p. 519-524, out./dez. 2011.

CARVALHO, N. M.; NAKAGAWA, J. Sementes: ciência, tecnologia e produção. 2.ed. Campinas: Fundação Cargill,1983. 429p.

ELLIS, R. H., HONG, T. D.; ROBERTS, E. H. Handbook of seed technology for genebanks: compendium of specific germination information and test recomendations. Roma: IBPGR, 1985. p.211667. v.2

FERREIRA, A. G.; BORGHETTI, F. Germinação do básico ao aplicado. Porto Alegre: Artmed, 2004.

GARCIA, J.; CÍCERO, S. M. Superação de dormência em sementes de Brachiaria brizantha cv. Marandu. Scientiae Agricola, Piracicaba, v. 49, n. 1: p. 9-13, 1992.

GASPAR-OLIVEIRA, C. M.et al. Manutenção da umidade do substrato durante o teste de germinação de Brachiaria brizantha. Revista Brasileira de Sementes, Brasília, v. 29, n. 3, p. 46-53, 2007.

LACERDA, M. J. R.et al. Superação da dormência de sementes de Brachiaria brizantha cv. "Marandu". Semina: Ciências Agrárias, Londrina, v.31, n.4, p.823-828, out./dez. 2010

MARTINS, L.; SILVA, W. R. Efeitos imediatos e latentes de tratamentos térmico e químico em sementes de Brachiaia brizantha cultivar Marandu. Bragantia, Campinas, v.62, n. 1, p. 81-83, 2003. 
MESCHEDE, D. K.et al. Tratamentos para superação da dormência das sementes de capim-braquiária cultivar Marandu. Revista Brasileira de Sementes, Brasília, v. 26, n. 2, p. 76-81, 2004.

POPINIGIS, F. Fisiologia da Semente. Brasilia, AGIPLAN, 1977. 290p.

PREVIERO, C. A.; GROTH, D.; RAZERA, L. F. Secagem ao sol e qualidade fisiológica de sementes de Brachiaria brizantha (Hochst. ex A. Rich.) Stapf. Revista Brasileira de Sementes, Brasília, v. 20, n. 2, p. 296-300, 1998.

SILVA, A. L. M. S.et al. Tratamentos para quebra de dormência em Brachiaria brizantha. Revista de Ciências Agrárias, Lisboa, v. 37, n.5, p. 37-41, 2014.

SILVA, F. A. S.; AZEVEDO, C. A. V. Versão do programa computacional Assistat para o sistema operacional Windows. Revista Brasileira de Produtos Agroindustriais, Campina Grande, v.4, n.1, p. 71-78, 2002.

SMIDERLI, O. J.; GIANLUPPI, V. Análise de Sementes de Gramíneas Forrageiras Tropicais. Boa Vista-RR: Embrapa Roraima, 2009. 16 p. (Documento 13).

SOUZA, F. F. Produção e qualidade de forragem de progênies de Brachiaria ruziziensis. 2007. 103 f. Dissertação (Mestrado em Zootecnia) - Universidade Federal de Lavras, Lavras, 2007.

VIEIRA, H. D.; SILVA, R. F.; BARROS, R. S. Superação da dormência de sementes de Brachiaria brizantha (hochst.ex a.rich) stapf cv. Marandu submetidas ao nitrato de potássio, hipoclorito de sódio, tiouréia e etanol. Revista Brasileira de Sementes, Brasília, v. 20, n. 2, p. 44-47, 1998. 
